\title{
HUBUNGAN DUKUNGAN KELUARGA DENGAN PERSONAL HYGIENE PASIEN JIWA DI WILAYAH KERJA PUSKESMAS WARA KOTA PALOPO TAHUN 2020
}

\author{
The Relationship between Family Support and the Personal Hygiene of Mental Patient in \\ Wara Public Health Centre, Palopo City In 2020
}

\author{
Ratnasari Iskandar, Febriani Eka Putri
}

Fakultas Kesehatan, Universitas Mega Buana Palopo

\section{Riwayat artikel}

Diajukan: 9 Juni 2021

Diterima: 9 Agustus 2021

Penulis Korespondensi:

Ratnasari Iskandar

Fakultas Kesehatan,

Universitas Mega

Buana Palopo

e-mail:

rsariskandar@gmail.com

\section{Kata Kunci:}

Personal Hygiene, Family

Support, Self-Care Deficit

\begin{abstract}
Abstrak
Pendahuluan : Perawatan diri (Personal Hygiene) aktivitas yang dilakukan utnuk memenuhi kebutuhan perawatan diri sehari-hari, cara untuk memelihra kesehatan fisik dan psikis. Masalah Personal hygiene atau defisit perawatan diri pada pasien jiwa merupakan masalah yang paling sering terjadi, karena penderita gangguan jiwa mengalami keterbatasan dalam melakukan aktivitas sehari-hari secara mandiri. Tujuan: Untuk mengetahui hubungan dukungan keluarga dengan personal hyegiene pada pasien gangguan jiwa di Puskesmas Wara, Kota Palopo tahun 2020. Metode: Penelitian ini menggunakan metode penelitian cross sectional, populasi dalam penelitian ini adalah semua pasien jiwa diwilayah kerja puskesmas wara kota palopo, pengambilan sampel dilakukan dengan Teknik purposive sampling didapatkan 43 responden. Pengumpulan data menggunakan kuesioner dan lembar observasi. Data yang telah dikumpulkan kemudian diolah dan dianalisis dengan komputer menggunakan uji Chi Square. Hasil: Analisis univariat mencari distribusi frekuensi, analisis bivariat didapatkan hubungan dukungan keluarga dengan personal hygiene $(\rho=, 003)$ dengan P Value 0,05. Kesimpulan: Baik dan kuranngnya persona hygiene pasien dengan gangguan jiwa berhubungan dengan baik dan kurangnya kemampuan keluarga memberikan dukungan kepada pasien. Hal ini sangat dipengaruhi oleh kemampuan dari segi financial dan pengetahuan keluarga
\end{abstract}

\section{Abstract}

Background: Introduction: Personal Hygiene (Personal Hygiene) Activities conducted to meet the needs of daily self-care, how to maintain physical and psychological health. Personal Hygiene problems or self-care deficits in mental health patients are the most common problems because people with mental disorders experience limitations in carrying out daily activities independently. Objective: To find out the relationship of family support with Personal Hygiene in a mental disorder patient at the Puskesmas Wara, Palopo City of 2020. Method: This study uses cross-sectional research methods, the population in this study are all mental health patients in the working center of the Palopo City Health Center, the sample was carried out with a purposive sampling technique obtained 43 respondents. Data collection uses questionnaires and observation sheets. The data collected was then processed and analyzed with a computer using the Chi-Square test. Results: Univariate analysis seeking frequency distribution, the bivariate analysis found relations with family support with personal hygiene ( $\rho=$, 003) with p-value 0.05. Conclusion: Good and the Persona Hygiene Patient with a mental disorder is well associated and the lack of family's ability to provide support to the patient. This is strongly influenced by the ability in terms of financial and family knowledge. 


\section{PENDAHULUAN}

Keluarga adalah unit pertama dari seseorang untuk mempelajari sesuatu dan dapat berkembang, keluarga merupakan perantara kebutuhan dan harapan anggota keluarga yang lain serta masyarakat, keluarga juga memenuhi kebutuhan psikolgis anggota keluarga dengan kasih sayang, kebutuhan ekonomi, dan kebutuhan seksual, keluarga sangat berpengaruh dalam pembentukan identitas seseorang dan juga harga dirinya. (1)

Peran keluarga diperlukan selama proses pengobatan pasien dengan gangguan jiwa, hal ini yang membuat pentingnya sebuah keluarga, karena sebuah keluarga adalah kelompok kecil yang paling sering berkomunikasi dengan pasien, keluarga adalah factor yang paling penting membantu penyembuhan pasien, karena penderita penyakit jiwa mengalami suatu gangguan pada mentalnya sehingga membuat tidak lengkapnya perkembangan mereka dalam berpikir seperti gangguan intelektual dan fungsi sosial yang disertai dengan pikiran tak bertanggung jawab atau agresif abnormal (5)

Masalah Personal hygiene atau deficit perawatan diri pada pasien jiwa merupakan masalah yang paling sering terjadi, karena penderita gangguan jiwa mengalami ketidakmampuan untuk melakukan perawatan diri dan aktivitas sehari-hari secara mandiri

Badan yang mengurus kesehatan dunia World Health Organization (WHO pada tahun 2019, tercatat sebesar 367 juta jiwa orang yang menderita gangguan jiwa di dunia ini

Berdasarkan hasil penelitian dari Livana (3) didapatkan hasil bahwa terdapat pengaruh antara persepsi atau pandangan keluarga terhadap dukungan keluarga dalam melakukan perawatan pada penderita gangguan jiwa di kecamatan Blang Bintang kabupaten Aceh Besar. semakin baik hubungan interaksi dalam sebuah keluarga maka akan makin baik juga dukungan yang akan diberikan oleh keluarga terhadap pasien dengan gangguan jiwa.

Dan dari penelitian yang telah dilakukan oleh Irnawat (2) di dapatkan hasil semakin baik peran anggota keluarga dalam memenuhi personal hygiene pasien dengan gangguan jiw maka semakin baik pula status personal hygiene anggota keluarga penderita skizofrenia

Faktor yang mempengaruhi kemampuan dalam kemandirian merupakan hasil dukungan dari lingkungan sekitar terutama dari keluarga. Mereka yang mempunyai kelainan mental memiliki intelektual yang rendah dan proses berpikir yang lamban yang membuat para penderita gangguan jiwa mengalami keterhambatan dalam melakukan aktivitas salah satunya yaitu dalam hal merawat diri seperti toileting, mandi dan berhias

\section{METODE}

Penelitian ini bersifat analitik denga metode yang digunakan adalah metde survey melalui wawancara dengan menggunakan kuesioner dengan pendekatan Cross Sectional yang berfokus pada waktu pengukuran/observasi untuk variabel dukungan keluarga dan variable personal hygiene pasien dengan gangguan jiwa pada satu saat dengan jumlah populasi 43 responden dan jumlah sampel 43 responden (Purposive Sampling). Data dianalisis dengan menggunakan program statistik (SPSS) versi 20. 
HASIL PENELITIAN

1. Analisa Univariat

A. Karakteristik Responden Jiwa

\begin{tabular}{lcc}
\hline \multicolumn{1}{l}{ Variabel } & $\boldsymbol{F}$ & $\mathbf{\%}$ \\
\hline Umur : & & \\
$<\mathbf{2 5}$ tahun & 12 & 27,9 \\
$\mathbf{2 6 - 3 5}$ tahun & 16 & 37,2 \\
$\mathbf{3 6 - 4 5}$ tahun & 15 & 34,9 \\
\hline Total & $\mathbf{4 3}$ & $\mathbf{1 0 0}$ \\
\hline Jenis Kelamin : & & \\
Laki-laki & 11 & 25,6 \\
Perempuan & 32 & 74,4 \\
\hline \multicolumn{1}{r}{$\quad$ Total } & $\mathbf{4 3}$ & $\mathbf{1 0 0}$ \\
\hline
\end{tabular}

Tabel 1. Distribusi frekuensi responden umur dan jenis kelamin di Wilayah Kerja Puskesmas Wara Kota Palopo $(n=43)$

Berdasarkan table 3.2 mengenai karakteristik responden pasien jiwa di wilayah kerja puskesmas wara bahwa mayoritas responden yang mengalami gangguan jiwa adalah wanita yaitu sebanyak
32 orang $(74,4 \%)$ dan yang paling banyak pada kategori usia yaitu pada usia dewasa awal sebanyak 16 orang $(37,2 \%)$ dari keseluruhan total responden.

\section{B. Variabel Penelitian}

\begin{tabular}{lccc}
\hline \multicolumn{2}{c}{ Dukungan Keluarga } & $\boldsymbol{f}$ & $\boldsymbol{\%}$ \\
\hline Baik & & 26 & 60,5 \\
Kurang & 17 & 39,5 \\
& Total & $\mathbf{4 3}$ & $\mathbf{1 0 0}$ \\
\hline
\end{tabular}

Tabel 2. Distribusi Frekuensi Berdasarkan Dukungan Keluarga Di Wilayah Kerja Puskesmas Wara Tahun $2020(n=43)$

Dari tabel 3.3 di atas didapatkan hasil dukungan keluarga sebanyak 26 orang $(60,5 \%)$ responden dengan dukungan keluarga baik dan 17 orang $(39,5 \%)$ dukungan keluarga kurang.

\begin{tabular}{lccc}
\hline & Personal Hygiene & $\boldsymbol{F}$ & $\boldsymbol{\%}$ \\
\hline Baik & & 30 & 69,8 \\
Kurang & & 13 & 30,2 \\
& Total & $\mathbf{4 3}$ & $\mathbf{1 0 0}$ \\
\hline
\end{tabular}

Tabel 3 Distribusi Frekuensi Berdasarkan Personal Hygiene Pasien Jiwa Di Wilayah Kerja Puskesmas Wara Tahun $2020(n=43)$ 
Dari table 3.4 diatas terlihat bahwa Distribusi responden personal hygiene sebanyak 30 orang $(69,8 \%)$ responden berstatus personal hygiene baik dan 13 orang $(30,3 \%)$ berstatus personal hygiene kurang.

\section{Analisa Bivariat}

\begin{tabular}{|c|c|c|c|c|c|c|c|}
\hline \multirow{3}{*}{$\begin{array}{l}\text { Dukungan } \\
\text { Keluarga }\end{array}$} & \multicolumn{6}{|c|}{ Personal Hygiene } & \multirow{2}{*}{$P$ Value } \\
\hline & \multicolumn{2}{|c|}{ Baik } & \multicolumn{2}{|c|}{ Kurang } & \multicolumn{2}{|c|}{ Total } & \\
\hline & $\mathbf{n}$ & $\%$ & $\mathbf{n}$ & $\%$ & $\mathbf{n}$ & $\%$ & \multirow{4}{*}{0,003} \\
\hline Baik & 23 & 53,5 & 3 & 7 & 26 & 60,5 & \\
\hline Kurang & 7 & 16,3 & 10 & 23,3 & 17 & 39,5 & \\
\hline Total & 30 & 69,8 & 13 & 30,2 & 43 & 100 & \\
\hline
\end{tabular}

Table 4. Tabulasi silang antara dukungan keluarga dengan personal hygiene pasien jiwa di puskesmas wara kota palopo tahun 2020

Dari hasil tabel 3.5 di atas responden dengan kategori dukungan keluarga baik dan mengalami personal hygiene baik sebanyak 23 orang $(53,5 \%)$, responden dengan dukungan keluarga kurang dan mengalami personal hygiene baik sebanyak $7(16,3 \%)$, responden dengan kategori dukungan keluarga baik dan mengalami personal hygiene kurang sebanyak 3 orang $(7 \%)$ dan responden dengan dukungan keluarga kurang dan mengalami personal hygiene kurang sebanyak 11 orang $(25,6 \%)$. Angka P Value 0,003 menunjukkan tingkat signifikansi, karena tingkat signifikansi $0,003<0,05$ maka $\mathrm{H}_{0}$ ditolak yang artinya ada hubungan dukungan keluarga dengan personal hygiene pasien jiwa di wilayah kerja puskesmas wara kota palopo tahun 2020.

\section{PEMBAHASAN}

Pada tabel 3.3 distribusi frekuensi responden untuk dukungan keluarga di wilayah kerja puskesmas wara didapatkan hasil dukungan keluarga baik sebanyak 26 orang $(60,5 \%)$ dan dukungan keluarga kurang sebanyak 17 orang $(39,5 \%)$. Hal ini sesuai dengan penelitian dari Mutmainnah 2018 (4) mengatakan bahwa sebagian besar pasien dengan dukungan keluarga baik akan mendapatkan dukungan emosional yang baik juga dari keluarga. ditandai dengan keluarga senantiasa berada di samping pasien, menjaga pasien, merawat dan memenuhi kebutuhannya

Tidak mampunya seseorang dalam merawat diri seperti minum, makan, mandi, berhias, dan toileting secara mandiri dengan bersih. Oleh karena itu personal hygiene yang menurun dengan fakta yang ditemukan di lapangan pasien atau penderita tersebut terlihat tidak terurus, bau serta terlihat mengalami gangguan kesehatan terutama pada kulitnya (6)

Berdasarkan hasil observasi langsung dilapangan pada saat melakukan penelitian, penampilan rata-rata dari para responden sudah terurus dari segi berpakaian dan kebersihan kulit hanya saja ada beberapa bagian yang keluarga tidak perhatikan secara mendetail, seperti kebersihan kuku dan rambut serta menggosok gigi, mungkin hal ini terlihat sepeleh tetapi bagi pasien jiwa hal ini sangat penting agar mereka dapat diterima dilingkungan sosial dan dapat terhindar dari penyakit lain.

Dari hasil penelitian dukungan keluarga dengan 43 responden terdapat 10 orang $(23,3 \%)$, dukungan keluarga kurang kepada pasien yang menyebabkan pasien kurang memperhatikan kebersihan diri sehingga berdampak pada personal hygiene yang buruk. Personal hygiene pasien berdampak juga pada kesehatan fisiknya. Tidak tersedianya waktu dan fasilitas untuk memenuhi keperluan pasien karena alasan biaya perawatan pasien karena rata-rata responden berasal keluarga yang kurang.

Pernyataan ini sejalan dengan penelitian dari (Titisari, 2015) mengatakan keluarga menjadi salah satu faktor yang mempengaruhi keyakinan dan nilai kesehatan anggota keluarga juga dapat menentukan perawatan yang tepat untuk anggota keluarga. Lalu penelitian dari (Irnawati et al., 2016) mengatakan bahwa dukungan keluarga sangat penting dalam memenuhhi kepatuhan pasien selama menjalani pengobatan

(Livana et al., 2018) mengatakan bahwa bila dukungan keluarga kurang akan membuat 
personal hygiene pasien pun kurang karena jika keluarga tidak memberikan dukungan, waktu, serta motivasi untuk pasien maka pasien tidak akan memperhatikan perawatan dirinya dengan baik.

\section{KESIMPULAN}

Baik dan kurangnya personal hygiene pasien dengan gangguan jiwa berhubungan dengan baik dan kurangnya kemampuan keluarga memberikan dukungan kepada pasien. Hal ini sangat dipengaruhi oleh kemampuan dari segi financial dan pengetahuan keluarga.

\section{SARAN}

Diharapkan bagi peneliti selanjutnya untuk dapat mengembangkan penelitian dengan mengambil variabel lain seperti tingkat kemandirian pasien jiwa dalam merawat diri dan hal-hal yang menyangkut personal hygiene agar penelitian ini dapat berkembang ke arah yang lebih baik dan juga sebagai sumber informasi agar pasien jiwa lebih dapat diperhatikan oleh lingkungan sosial contohnya seperti keluarga serta masyarakat.

\section{DAFTAR PUSTAKA}

Andarmoyo, S. (2012). Keperawatan Keluarga Konsep Teori, Proses dan Praktik Keperawatan (Pertama). Graha Ilmu.

Irnawati, N. M., Siagian, I. E. T., \& Ottay, R. I. (2016). Pengaruh dukungan keluarga terhadap kepatuhan minum obat pada penderita tuberkulosis di puskesmas motoboi kecil kota kotamobagu. IV.

Livana, Hermanto, \& Pratama Putra, N. (2018). Dukungan Keluarga Dengan Perawatan Diri Pada Pasien Gangguan Jiwa di Poli Jiwa. Kesehatan Manarang, 4. http://jurnal.poltekkesmamuju.ac.id/index. $\mathrm{php} / \mathrm{m}$

Mutmainnah, S. (2018). Hubungan Peran Keluarga Dalam Pemenuhan Personal Hygiene Dengan Status Hygiene Pada Penderita Skizofrenia ( Studi Di Wilayah Puskesmas Karangjati Kabupaten Ngawi) The Relationship of Family' $s$ Role in Fulfilling Personal Hygiene with Status $\begin{array}{llll}\text { Hygiene } & \text { in }\end{array}$ http://jurnal.akperngawi.ac.id

Nirwan, Tahlil, T., \& Usman, S. (2016). Dukungan Keluarga Dalam Perawatan Pasien Gangguan Jiwa Dengan Pendekatan Health Promotion Model. Jurnal Ilmu
Keperawatan, 4(2).

Nurwulan, D. (2017). Hubungan Dukugan Keluarga dengan Tingkat Kecemasan Pada Pasien Pre Anestesi Dengan Tindakan Spinal Anestesi di RSUD Sleman. 1-11.

Rusnita, \& Syarifuddin. (2019). Dukungan Keluarga pada Klien yang Mengalami Gangguan Jiwa di Wilayah Kerja Puskesmas Ulee Kareng Kota Banda Aceh. Journal of Healthcare Technology and Medicine, $5(1), 118$. https://doi.org/10.33143/jhtm.v5i1.338

Titisari, L. (2015). Hubungan Dukungan Keluarga Dengan Kemandirian Personal Hygiene Anak Prasekolah di TK ABA Milangi Gamping Sleman Ygyakarta.

Yudhana, S. A. (2017). Upaya Meningkatkan Personal Hygiene Melalui Motivasi Perawatan Diri Pada Pasien Defisit Perawatan Diri. 